\title{
“Comprovisation or Imposition?": An Improvised Composition on a Life of Improvisation
}

\section{Jesse Stewart}

I would like to begin by saying that it is a great pleasure to be back in Guelph, which, in many ways, still feels like home to me even though I haven't lived here for four years. It is wonderful to see so many friends and old acquaintances and also to have a chance to make new ones. ${ }^{1}$

Over the past 9 days, I have been involved in the Improvisation, Community, and Social Practice Summer Institute. I was originally scheduled to be on a train right now heading home to Ottawa, as I have to teach at Carleton University tomorrow morning. I had been lamenting the fact that I was going to miss the Guelph Jazz Festival and Colloquium this year for the first time in 19 years. In fact, I think I have performed at all but one edition of the festival, so it was a disappointment to me that I was going to miss the whole festival and colloquium this year. Imagine my surprise this past Friday when Ajay told me that the Gwen Ansell, one of the keynote speakers for this year's colloquium, had to cancel and Ajay was wondering if I would consider filling in for her. I accepted his kind invitation and so here we are. My apologies to those of you who came this morning expecting to hear Gwen Ansell talk about her work in South Africa. My apologies also go out to those of you who came expecting a polished piece of deeply theoretical academic scholarship. I didn't think I would be able to pull that off with only a few days to prepare. So I decided instead that I would do something that I don't do very often in academic settings: talk about my own work as both a student and teacher of improvised music.

The first part of the title of my talk_-Comprovisation or Imposition?"-comes from an exchange that I had with my composition teacher, the late James Tenney, when I was studying with him at York University between 1997 and the year 2000. During one of our composition seminar meetings, he commented on the fact that all of the work that I was doing at the time combined composition and improvisation. In response, I expressed my discomfort with both terms, and the fact that they are so often seen as binary opposites when, in fact, there is a whole range of musical practices that combine elements of both. I suggested to him that maybe we need to come up with a new theoretical framework for contemporary modes of music making and a new term that is more inclusive and more accurate. "What about 'comprovisation"' I said, coining a portmanteau term that I naively thought was original to me. Tenney replied with a smile: "Maybe. But it can also be an 'imposition."' That statement sort of summed up Jim's attitude towards improvisation, which was somewhat ambivalent.

I mention this story not to criticize James Tenney in any way. Indeed, I had a tremendous amount of respect for him then as I do now, and he shaped my approach to music making in many ways. Rather, I mention this story about "comprovisation or imposition" because it highlights some of the power dynamics involved in the discourses that surround contemporary music. Moreover, that exchange and many others since have made it clear to me that my own creative practice-as well as my research and pedagogical practice-don't always line up neatly with the dominant frameworks that surround knowledge production, especially within the academy. So, for the purposes of my talk today, and in keeping with the colloquium's theme of "Pedagogy \& Praxis: Improvisation as Social Justice and Social Responsibility," I thought I would discuss how I came to do the work that I do, reflecting on my experiences as both a student and teacher of musical improvisation, using those experiences as a way to raise some questions about the ways in which improvisation pedagogy might intersect with the ideas of social justice and social responsibility.

Many musicians I know can trace their love for music back to one or two events early in their childhood-maybe it was the first time they heard a recording of the Beatles or the first time they heard record scratching-some musical or sonic event that caught their ears and their imagination, hooking them on music for life. My first musical epiphany stemmed from a rather humble source - a metal bucket. When I was five years old, my kindergarten teacher gave our class an assignment to make a musical instrument, so I went home to my grandparents' house and rummaged around in their basement looking for materials that I could use to make an instrument. I came across a metal pail: not a wash bucket, more like a five-gallon pail made of metal. Grabbing a pair of wooden spoons from the kitchen, I turned the pail upside down and began playing it like a drum, creating a deafening cacophony of sound. But the real magic came when I turned the bucket right side up and balanced it as best I could on the palm of my five-year old left hand. Making a fist in my right hand, I struck the side of the pail, eliciting a deep, gong-like tone that to me was pure magic. I don't know if it was the sound itself that captured my imagination so much as it was the fact that I had made it. I had discovered that bucket and repurposed it so that it was no longer just a bucket; it was a glorious musical instrument. I proudly brought my bucket to school the next day and all the students in the class went around the circle sharing our musical creations. Some of the other instruments may have looked better than mine; but to my ears, none came even close to my pail in sheer sonic beauty or in volume. When it was my turn, I inverted the pail and played on 
the bottom with the wooden spoons as mightily as I could and then I flipped it over and elicited the beautiful gong sound. My teacher, Mrs. Avery, was unimpressed. "Jesse, it's just a pail," she said flatly. "No it's not," I said. "Listen." And I repeated my earlier actions. Still not convinced, she gave me a grade of B- on my pail, the first musical instrument I ever made or played.

I mention this story for a couple of reasons. First, that moment is the earliest act of musical improvisation that I can remember in my own life and it had a profound impact on me. The sense of wonder and discovery that I felt in that moment in my grandparent's basement is something that I have looked for and listened for my whole life. Most kids bang around on pots and pans and buckets at some point early in life. Unlike most kids, I never stopped doing those things. And I think that the power of that early experience had something to do with my continued sonic explorations. The other reason that I mention that experience is that it highlights two contexts which frame our early encounters with musical improvisation: the home and the school. Part of the reason that I continued to bang on pots and pans and the like is that my grandparents and mother never told me to shut up. They actually encouraged me. I was not so lucky when it came to my experience in school. For whatever reason, Mrs. Avery didn't see what I saw or hear what I heard in that bucket. I don't begrudge her for that, nor for the fact that she gave me a less than stellar grade on a project that I was really excited about. But I do think that as teachers, we need to be very careful when we evaluate the creative work of our students, especially in the case of young students. It is so easy to turn a kid off music for life. I meet a lot of adults who tell me that they are not musical. When I ask them why they think that, almost invariably they tell me about something negative that someone in a position of authority said to them early in their life-usually a schoolteacher or a choir director-something that embarrassed them so much that they internalized it, convincing themselves that it was true. And they stopped making music as a result. That is a tragedy. If we really want to develop a pedagogical praxis of musical improvisation that emphasizes social responsibility and social justice, I think we need to start in our homes and in our schools, encouraging children to experiment, and fostering the spirit of creative play that is inherent in all children, certainly in every child that I have ever met. All too often, our schools end up doing the opposite: encouraging conformity and stifling creativity.

My experience with the metal pail was my first "aha moment," musically speaking. Ten years later, I had another transformative experience that took place in a very different learning environment. By the time I reached high school, I had started playing the drum set. At first, I played in a few rock bands. Eventually I started listening to fusion groups of the time, bands like Spyro Gyra and Pat Metheny Group. Like a lot of young musicians, I sort of came to jazz backwards as I gradually deepened my knowledge of the music that preceded the fusion groups that I was listening to.

I went to my first performance of live jazz when I was fifteen years old and that was a life-changing experience for me. One of my friends in high school who was more in the know than I was when it came to jazz said to me: "A famous jazz drummer named Elvin Jones is coming to Toronto. Let's go check him out." And so he and I went to Toronto to a club on Bloor Street called the Bermuda Onion that has been closed for many years now. We arrived quite early. The only other people in the club when we arrived were the members of the band. I don't remember the full personnel but I think Sonny Fortune was playing tenor saxophone, as was Pat LaBarbera who was a special guest that night. And of course, Elvin Jones and his partner Keiko were there as well. My friend and I hadn't been seated long when who should come to our table but Elvin Jones. He talked with us and I remember him shaking my hand. I remember it for two reasons: first, he had very large hands and I remember the feeling of my hand disappearing into his. The other reason that I remember that handshake so vividly was that it was the warmest handshake that I have ever received. There seemed to be a level of sincerity in that handshake that was unlike any other I had experienced before (or since for that matter). Elvin Jones seemed genuinely happy to meet us, happy that there were two white kids who traveled from the middle-class suburbs to Toronto to listen to his group.

At this point I want to intervene for a moment in the story that I am telling and use a critical lens to examine the material conditions that made that moment possible. Looking back, I am aware of the fact that the relative affluence afforded by my middle-class upbringing enabled me to pay the 12 dollars to take the Go Train to and from Toronto and pay the $\$ 20$ cover charge to get into the club. I know for a fact that many of my peers simply could not have afforded to do that. I also have to thank my mother and stepfather for letting me go to Toronto to hang out in jazz clubs until the wee hours of the morning almost every weekend from the time I was fifteen. I am not so sure that I would be as permissive as a parent, but I appreciate the fact that they supported me because those early experiences were fundamentally important to my development as an improvising musician.

Now back to my story about Elvin Jones: when the band started to play, it was a profoundly moving and transformative experience that changed me at such a fundamental level that I can't really describe it. But what I can say is that it wasn't Elvin's musicality that affected me so deeply, nor his impressive technique, or even the intensity of his playing - all of which were truly remarkable and affective. What left an indelible mark on me as a musician and as a person was the extraordinary level of conviction and commitment that I heard in his playing-it was the same 
level of sincerity that I felt in that handshake earlier that night. It was clear to me that he put all of himself into every note that he played-almost as if his life depended on it. That is what I was thinking as I was listening to him for the first time and indeed to live jazz for the first time in my life. Needless to say, it was a remarkable introduction. I walked out of the club that night and I thought to myself: "Either I am going to dedicate my life to music; or I will never play drums again." There was no longer an in-between for me. For better or for worse, I chose to dedicate my life to music, to jazz and musical improvisation more specifically.

That performance embodied what I consider to be one of the most significant lessons I have ever learned about musical improvisation: the importance of commitment, commitment to one's craft and to the years of practice, hard work, and dedication that developing an improvisatory practice entails, and commitment to one's musical actions in the improvisatory moment. That is one of the things that I value most highly in musical improvisation and in the experience of music generally as both a listener and a performer-when there is a clear and deep sense that the musicians involved are putting everything of themselves into the musical choices that they make. If we don't commit to our own actions as improvisers-or for that matter, as scholars and teachers-how can we possibly expect anyone else to commit to what we are doing and actively engage with our work? That is an important lesson, but it is also one of the most difficult lessons to teach to anyone else. We can strive to lead by example in that regard, as Elvin Jones did for me, so many years ago. We can also create learning opportunities for ourselves and for others aimed at cultivating a sense of wonder that can hopefully lead to those kinds of transformative experiences and that level of commitment.

My experiences at the Bermuda Onion and at the other Toronto jazz clubs that I started frequenting on a regular basis shortly after that experience highlight another important context in which the pedagogy of improvisation can take place-at clubs, music festivals, and other performance venues that feature improvisatory modes of music making. Such venues not only create a framework for the production and reception of improvised music, but also serve as alternative pedagogical contexts for the training of musicians whose creative interests don't necessarily line up with the dominant musical curriculum that is taught in most public schools, colleges, and universities in North America. Think of the importance of the Velvet Lounge as a breeding ground for creative musicians on Chicago's south side, or Tonic in New York City, which closed down in 2007, or now The Stone in New York City. For improvising musicians in and around Toronto, a performance venue called Somewhere There has had an enormous impact on the Toronto scene in recent years - it has not only created a real sense of community among many Toronto improvising musicians, it has also created a learning environment for the exchange of musical ideas. And, of course, here in this community, the Guelph Jazz Festival and Colloquium have played a vital role in providing opportunities for musicians and audience members alike to hear new sounds, to forge new relationships, and to exchange musical ideas. The jazz festival certainly has been crucial to my own development as an improviser, and I think that is true for many others as well.

Around the same time that I started going to hear live performances of jazz, I started listening to jazz recordings voraciously and that was also a very important part of my education in jazz and in improvisation: listening to recordings, playing along with those recordings and trying to figure out what was going on in the playing of the great jazz drummers I was starting to listen to-people like Kenny Clarke, Max Roach, Art Blakey, Philly Jo Jones, Roy Haynes, Tony Williams, and, of course, Elvin Jones. When I look back on that period of my life, and when I think about the pedagogy of jazz and improvised music more generally, it is clear to me that self-study-or autodidacticism —is a fundamental part of learning how to improvise. There are also many valuable study aids aimed at the budding jazz improviser especially when it comes to improvising in a "straight ahead" jazz context, and there are many more resources now than there were then. Now, as then, spending time listening to the music and practicing one's instrument are essential parts of learning to improvise.

As important as various forms of self-study are, I think mentorship is also fundamentally important. While I was in high school, I started studying drums with a man named Dave Stevason, a name that I doubt any of you would know. He passed away 11 years ago. He was a very good teacher, but he was rather reclusive when it came to public performance. In fact, I never once heard him perform music in public in the 20 years that I knew him. Our lessons covered some of things one would expect: drum set technique, the importance of developing good time keeping, musicality in phrasing, facility in playing a wide range of styles of music and different types of grooves. He also loaned me many recordings that I didn't know about or couldn't find elsewhere. He encouraged me to always listen closely to the other members of any ensemble I played with and to know where I was in the structure of the music I was playing at all times. Those were all valuable lessons. There were also lessons that were not explicitly musical. For example, once when I was late for a lesson, he spent the entire two-hour lesson lecturing me on the importance of punctuality, a lesson I didn't soon forget. He also used my tardiness as a way of emphasizing that all of our actions-musical and otherwise-have an impact on others, so we need to do our best to act in an ethical and responsible manner to the greatest extent possible. That was an important lesson that continues to resonate for me 
to this day, and one that has clear implications for the idea of a socially responsible and socially just model of the pedagogy of improvisation.

Since that time, I have been very fortunate to have had many wonderful and inspiring mentors that have shaped not only my approach to musical improvisation, but also the way in which I see the world-people including David Mott, James Tenney, George Lewis, Paul Haines, and Pauline Oliveros, to name only a few. These people have been mentors to me, and to many others of course, not only because they have generously shared their ideas, but also because they live their lives in such a way that they are an embodiment of the lessons they teach. To me, that is a truly remarkable pedagogical praxis and it is another lesson about commitment-putting the ideas that we teach into practice as consistently as possible, whether we are on the bandstand or in the classroom. I have been fortunate to have had many inspiring mentors within the university environment as well, including several people associated with the Guelph Jazz Festival and Colloquium, namely Ajay Heble, Daniel Fischlin, Ric Knowles, Christine Bold, and Ellen Waterman. Following their examples, I would now like to discuss some of my experiences of improvisation within the academy.

I first came to the University of Guelph as an undergraduate student in 1993. I came here initially to study visual art. I made a conscious decision at the time that I did not want to go to any of the three major jazz programs in Southern Ontario: York University, Humber College, or the University of Toronto. I was rather strong-headed about that-and quite possibly wrong-headed_but I felt that the models of jazz education being espoused by those schools at that time were sufficiently conservative that I worried that they would be creatively stifling. So I decided that I would not study jazz formally at the college or university level and I would instead focus on the study of visual art at the University of Guelph. Truth be told, I did not know prior to my arrival here that the University of Guelph had a music program. But I quickly discovered that it did and so I began taking some classes and eventually I earned a double major in both Fine Art and Music. Musical improvisation was not a part of the curriculum at the time. Like many university music programs, there was one survey course in jazz history and a university jazz ensemble, both of which I participated in. Otherwise, I was taking classes in Western music theory, ethnomusicology, musicianship, and the history of Western art music.

Interestingly, my professors in the Fine Art program—including Reinhard Reitzenstein, Suzy Lake, John Filion, and Ron Shuebrook-were very interested in, and supportive of, my work in the sonic arts. I don't know if the term "sound art" had been coined at that point. If it had, I had not heard it. But the fields of performance art, sound sculpture, and video art created an overlapping series of frames within which I felt free to experiment with sound in an improvisatory way outside of the structures and strictures of jazz as I understood them at the time. That was quite liberating for me, and it highlights something else about pedagogical praxis: there can be multiple roads into a particular field of creative and/or intellectual study, and sometimes the road less travelled can be a highly productive one. For me, there has been tremendous value in approaching my own creative practice from a disciplinary framework outside the one in which I create and in exploring the liminal spaces between different fields. That was one of the reasons that I did my doctoral work in the School of English and Theatre Studies at the University of Guelph. I don't know how many times people-including faculty members in the program-asked me what I was doing there. I suppose that the work that I was doing was another comprovisation that may have been perceived by some as an imposition on the epistemological and disciplinary conventions associated with the academic fields with which I engaged. I argue now, as I did then, that the spaces between different fields, and the dialogue that emerges as one travels between them, can be tremendously productive. The Improvisation, Community, and Social Practice project, which includes scholars from dozens of different disciplines, is a wonderful example of the richness that can result from interdisciplinary dialogue, as is the emergent field of improvisation studies more generally.

Having discussed some of my experiences as a student of improvisation, I thought I would use the time that remains to tell you a bit about some of the pedagogical initiatives that I have been involved with as a teacher over the past few years, initiatives in which I have tried to put some of the lessons that I have learned through my experiences as an improviser into practice or, more correctly, into praxis. In the past, I have tended to shy away from talking about the work that students in my classes have done in part because I would never want to be seen to objectify the students with whom I have had the good fortune of working. But I also recognize that if we really want the work that we do as educators to make a positive difference in the world, it is important that we share our experiences and our ideas in forums such as this.

When I arrived at Carleton University, I began teaching courses in music composition and orchestration. Each of the composition classes I have taught so far has been structured around a three-phase process in which we explore, in turn, the interdependent roles of composer, performer, and audience member, interrogating these categories and the power relationships that they entail. In the assignments that focus on the role of the composer, I ask students to find a way to communicate their musical intentions as precisely and thoroughly as possible. Although I don't set any limits on the style or genre of the music they create, the responses to that phase of the course tend to involve highly 
prescriptive scores in Western musical notation. In the next phase of the course, I ask students to develop a series of pieces that leave substantive musical decisions to the performer. The responses to this assignment vary greatly; sometimes they take the form of graphic scores, sometimes they are lead sheets, or game pieces, or works involving structured improvisation. The third phase of my composition classes focuses on the experiences of the audience member. For this one, the students work collaboratively to create some sort of sound installation that emphasizes the agency of the audience in determining the nature of their musical experience.

In response to this assignment, my senior composition class in 2012 worked together to create something called the "Carleton University Soundmap Project" or "CUSP." The students set out to make audio recordings of as many places on the university campus as possible. Then they created a website that features a map of the Carleton campus with the sounds keyed to the map (see www.carletonsoundmap.ca). By scrolling (and hovering) over certain areas of the map, visitors to the site trigger sounds that were recorded on the corresponding location on campus. Clicking on such an area will open a secondary window with information about that recording. Since more than one secondary window can be open at a time, visitors to the site can trigger multiple sound files at once, playing the Soundmap as a musical instrument. When we launched the site, we performed a public concert in which every member of the class was improvising on the soundmap using their laptop or smartphone hooked up to a PA system.

Although this project started out as a response to an assignment within the context of a composition class, it quickly took on a life of its own and the students realized that in addition to creating an interactive, improvisatory online sound installation, they were also creating something that might be of benefit to blind students who were thinking of coming to Carleton University and wanted to get a sense of the campus soundscape. Interestingly, the students in the course continued to work on the project well after the end of the semester and after their final grades had been submitted, suggesting that they felt a particularly high level of investment in the project.

I also teach an introductory undergraduate class in instrumentation and orchestration. In addition to focusing on the instruments of the Western symphony orchestra, I ask every student in the class to create a presentation and a handout on an instrument drawn from outside the realm of the symphony orchestra-in other words, instruments from popular, experimental, and non-western musical traditions. I also ask for a brief overview of the instrument-its history, its defining timbral characteristics, its register and range, playing techniques (both conventional and extended where appropriate), as well as notational conventions associated with the instrument if applicable. I make all of the presentation handouts from all of the years that I have taught the course available to students in the class to consult and revise. Having taught the course four times, we now have quite a comprehensive compendium of information about non-western instruments that functions almost like a complementary textbook in the class. One of the wonderful things about that assignment is that it provides an opportunity for many students to talk about instruments and modes of music making that represent their own cultural and musical backgrounds.

Another thing I do in that class is give the students a group project that takes the place of a final exam in the course. The group project asks them to develop an ensemble that is unique and innovative in its approach to instrumentation and then stage a public performance featuring that ensemble. On the course outline, I state:

The proposed ensemble must include everyone in the class, but does not necessarily have to reflect the existing instrumental proficiencies in the class (nor does it even have to involve traditional musical instruments!). This is an opportunity for you to think creatively about instrumentation. What does (or can) "instrumentation" mean in an age when composers can use virtually any sound as a viable sonic resource?

The course outline continues:

The intentions behind this assignment are: 1) to encourage students to think creatively about musical instrumentation 2) to develop creative problem solving skills and 3) to think about musical instrumentation and orchestration (and, indeed, music making generally) as social activities. When we create relationships between instruments, we also create relationships between people. This assignment provides an opportunity to think rigorously and creatively about the kinds of social relationships we want to create through music and in the classroom.

The responses to this assignment have been very interesting. The first year I taught the course, the class decided that they wanted to explore latex balloons as musical instruments, so they formed an ensemble called the Balloon Orchestra. Originally, the members of the class thought that this idea was unique to them. So I told them about the rich history of experimental balloon music, including the work of Judy Dunaway who uses balloons extensively in her own creative practice (and who has performed at the Guelph Jazz Festival). So we began researching the history of balloon music and worked together to develop many different kinds of balloon instruments. One of the members of 
the group even developed a form of graphic balloon notation. One of the interesting things about that project is the tremendous public response that the group received. The Balloon Orchestra was featured on CBC Radio twice within a few weeks of forming, and we went on to perform at multiple music festivals. So the learning process continued long after the academic semester ended.

The following year, the instrumentation class decided to explore paper and cardboard as a sonic resource. In 2011 , the class decided to explore the sonic properties of water, both on its own and in conjunction with other musical instruments. One of the pieces that we developed involved IV bags filled with water dripping onto the surface of three snare drums at different rates. Throughout the piece, each performer gradually opens the stop-caulk on the IV bag, changing the pulse rate. Once each bag is fully emptied, the performers play with sticks on the snare drums, generating a crescendo of sound and spray. Other instruments included waterphones, water-filled wine glasses, and hanging metal pans that we played by spraying them with concentrated streams of water from dozens of water bottles.

In each of these educational initiatives, I tried to create a framework within which the students could exercise creativity and agency on both an individual and group level. This process invariably involves both compositional and improvisational decisions and modes of interaction (another comprovisation). I always ask the students whether or not they would like me to be involved in the ensemble that they create, and I explain to them that they won't hurt my feelings if they would prefer to work on the project on their own. Thus far, each class has welcomed me into the ensemble. I do like to be involved for a few reasons: first, it's fun-it's much better than marking final exams or orchestration assignments. Second, it gives me an opportunity to nudge the project in certain directions if the collaborative process starts to unravel or if tensions arise. Third, it allows me to offer suggestions in a way that I think is perceived to be contributive rather than critical or evaluative. Finally, it reinforces the notion that every member of the class_-including me-has a shared responsibility in the learning process. In other words, I take seriously Paolo Friere's notion that in a truly radical critical pedagogy, both the students and the teacher should become coinvestigators of knowledge through critically-engaged dialogue that will hopefully encourage the curiosity of all parties involved and lead to true learning. Even within the context of an instrumentation class (which otherwise focuses on rather nuts-and-bolts material), I try to enact a pedagogical praxis that embraces both composition and improvisation and stresses social responsibility.

l'll mention one more pedagogical initiative that I have been involved with. Carleton University has a relatively new Master of Arts program in Music and Culture, and I was invited to propose and design a course for it. The end result was a course titled "Music and Social Justice" that explored the varied roles that music has played-and might be able to play - as an agent of positive social change in different contexts. The central question that animated the course was: "How can our work as performers, scholars, educators, and students of music participate in the transformation of unjust social relations and unequal distributions of power?" In many ways, it is the same question that animates this colloquium and this talk. We examined this question through a close reading of a variety of primary texts including the Universal Declaration of Human Rights as well as a wide range of secondary sources. In addition to asking the students to each write an essay on the subject of music and social justice, I asked the class to mount some sort of large-scale collaborative initiative that would explore music's capacity to act as a vehicle for positive social change. That was really the only parameter that I set for the group project. In response, the students decided to mount a symposium titled "Sound Changes: Music and Social Justice." The two-day event featured live performances of slam poetry, improvised music, and the politically-provocative avant-cabaret-pop of Friendly Rich and the Lollipop People. It also featured a joint keynote talk by Ajay Heble and Daniel Fischlin, as well as panel discussions, workshops, and presentations on topics including the role of music in the Occupy Movement, the role of hip hop in the Arab Spring, the political implications of the El Sistema movement, and more. The symposium brought together community activists, scholars, musicians, and other cultural workers from around the world. All of these people came together to explore the power of music to bring about social change, and they did so through a process of improvisatory dialogue. And that dialogue continued long after the symposium ended. The organizers and I received many emails from students, academics, and cultural workers from around the globe who are developing their own initiatives aimed at exploring and mobilizing the power of music to make a difference in the world. Although the project started out initially as a response to a classroom assignment, it facilitated-and continues to facilitate-the formation of alliances across many boundaries including those of nation, race, class, gender, sexual orientation, age, and the boundary line between the academy and the broader public sphere.

In conclusion, l'd like to return to the concepts of "comprovisation" and "imposition" that I introduced as a way of framing my experiences as both a student and teacher of improvised music. As the pedagogical initiatives that I described hopefully suggest, I still believe in the power and value of "comprovisation," of working in and through the liminal spaces between received binaries such as composition and improvisation, and between seemingly divergent disciplinary fields and epistemological frameworks. If those liminal activities are indeed an "imposition" on the 
dominant frameworks of knowledge production inside the academy or out, I think they are a necessary one if we are to perform, teach, and live a socially responsible pedagogical praxis of improvisation.

\section{Notes}

${ }^{1}$ This paper was first delivered as a keynote talk at the Guelph Jazz Festival Colloquium on 5 September 2012. 